\title{
APPLICATION OF THE HIGH-FREQUENCY ELECTRIC WELDING OF SOFT TISSUES IN ENUCLE- ATION OF THE EYEBALL FOR UVEAL MELANOMA
}

Pasechnikova N. V., Naumenko V. A., Maletskiy A. P., Vit V. V., Chebotarev E. P., Pukhlik E. S. Odessa, Ukraine

59 patients ( 24 men and 35 women) at the age of $6.0 \pm 10.5$ with uveal melanoma, with the tumor prominence of $7.2 \pm 3.1 \mathrm{~mm}$, of $14.0 \pm 4.2 \mathrm{~mm}$ in diameter who were subjected to enucleation with the help of high frequency electric welding have been investigated. The control group consisted of 20 patients ( 6 men and 14 women) at the age of $61.5 \pm 8.6$ with uveal melanoma, with the tumor prominence of $6.9 \pm 3.7 \mathrm{~mm}$, of $12.9 \pm 4.2 \mathrm{~mm}$ in diameter who were subjected to enucleation by the usual methods. The results obtained have shown that the use of high frequency welding for eye enucleation allows to avoid bleeding when muscles and neurovascular fascicle are crossed, to reach the necessary fixation of muscles to the tenon capsule and stable connection of the conjunctiva margins with each other without the use of any sutural material. The use of the given method reduces not only the time of surgery (on average by 6.6 minutes), saves the patients from the removal of stitches, but also can reduce the time the patient's stays in hospital by 2 days (i.e. $28.5 \%$ ) and therefore brings economic benefits. The established character of the postoperative course shows that the given method can be the method of choice if it is necessary to remove the eyeball.

УДК 617.77-006.6-097-092.18

\section{УРОВЕНЬ ЭКСПРЕССИИ АНТИГЕНОВ СD16+, СD25+, СD95+ ЛИМФОЦИТАМИ ПЕРИФЕРИЧЕСКОЙ КРОВИ БОЛЬНЫХ ЗЛОКАЧЕСТВЕННЫМИ ЭПИТЕЛИАЛЬНЫМИ ОПУХОЛЯМИ (ЗЭО) КОЖИ ВЕК ПРИ ПРОВЕДЕНИИ КОМБИНИРОВАННОГО ЛЕЧЕНИЯ (ЛУЧЕВАЯ ТЕРАПИЯ + КРИОДЕСТРУКЦИЯ)}

\section{И. А. Сафроненкова}

\author{
ГУ «Институт глазных болезней и тканевой терапии им. В. П. Филатова НАМН Украины»
}

\begin{abstract}
У 165 хворих на злоякісні епітеліальні пухлини (ЗЕП) шкіри повік і у 28 умовно здорових осіб вивчено рівень експресії антигенів $C D 16+, C D 25+, C D 95+$ лімфоцитами за допомогою однойменних моноклональних антитіл. Встановлено достовірне підвищення рівня експресії антигенів CD25+ $i$ CD95+, $i$ зниження експресії антигена CD16+ при ЗЕПу порівнянні з нормою. Це свідчить про зниження протипухлинного імунітету та придбанні здатності імунної системи до стимуляції росту пухлинних клітин. Достовірне зниження експресії антигенів CD25+ i CD95+ через 6 та 12 місяців після комбінованого лікування (променева терапія+кріодеструкція) свідчить про початок відновлення протипухлинного імунітету у хворих ЗЕП шкіри повік.
\end{abstract}

Ключевые слова: злокачественные эпителиальные опухоли кожи век, противоопухолевый иммунитет

Ключові слова: злоякісні епітеліальні пухлини шкіри повік, протипухлинний імунітет

Введение. Злокачественные эпителиальные опухоли (3ЭО) кожи - одно из наиболее распространенных онкологических заболеваний. Показатели заболеваемости за последние 10 лет в республиках СНГ составляют от 8,6 до 49,3 на 100000 населения [1, 5-7]. Ежегодно в мире регистрируется от 500 до 900 тысяч новых случаев заболевания и тенденции к снижению этой патологии не наблюдается [8 -10].

Немаловажную роль в возникновении и прогрессировании опухолевого процесса играет иммунная система, нормальной функцией которой является распознавание и отторжение опухолевых клеток. Однако в некоторых случаях опухоль не только теряет чувствительность к подавляющему действию иммунной системы, но и приобретает способность к использованию ее факторов для стимуляции роста [2]. К белкам, способным регулировать иммунные механизмы и выступать в качестве факторов ухода опухоли от иммунологического контроля, относятся мембранные антигены клеток иммунной системы, в частности антигены CD16+, $\mathrm{CD} 25+$ и $\mathrm{CD} 95+$. Нарушение их равновесного содержания в биологических жидкостях организма приводит к модуляции межклеточных мембранных взаимодействий и соответственно иммунного ответа. Выполняя роль межклеточных коммуникаторов, они связываются с лигандами своих мембранных

(С) И. А. Сафроненкова, 2012 
гомологов на поверхности клеток и препятствуют передаче сигнала от клетки к клетке, что приводит к супрессии иммунного ответа. Являясь продуктом одной клетки, антигены могут выступать в качестве трансмиттера, активирующего или подавляющего функцию другой клетки вплоть до инициации ее гибели путем апоптоза [3].

Изменения иммунного статуса вызывает и проведение противоопухолевого лечения. Реализация лечебного эффекта происходит не только за счет повреждающего действия физических лечебных факторов, а и путем активации различных биологических механизмов, направленных на углубление деструкции поврежденных клеток и резорбцию. В связи с этим, мембранные антигены CD16+, CD25+, CD95+ можно рассматривать в качестве эндогенных иммунорегуляторов, тесно связанных с работой всех звеньев иммунитета [3]. Поэтому мониторинговое исследование их экспрессии при проведении комбинированного лечения больным ЗЭО кожи век позволит установить некоторые механизмы формирования противоопухолевой резистенции. Это, в свою очередь, позволит индивидуализировать подход к выбору лечения, возможно с включением в него иммунокорригирующих препаратов.

Цель работы: изучение уровня экспрессии антигенов CD16 +, CD25+ и CD95+ на лимфоцитах периферической крови больных $3 Э О$ кожи век в динамике после проведения комбинированного лечения (лучевая терапия + криодеструкция).

МАТЕРИАЛ И МЕТОДЫ ИССЛЕДОВАНИЯ. Исследование проведено у больных $3 Э О$ кожи век, проходивших лечение в ГУ «Институте глазных болезней и тканевой терапии им. В. П. Филатова НАМН Украины» (у 165 пациентов - до начала лечения и у 100 - в динамике через 6 и 12 месяцев после лечения). Средний возраст больных $(63,5 \pm 11,7)$ лет. Мужчин было $74(44,8 \%)$, женщин - 91 $(55,2 \%)$. Базальноклеточный рак верифицирован у 129 $(78,2 \%)$ больных, плоскоклеточный - у $22(13,3 \%)$ и метатипический - у 14 (8,5 \%). Контрольную группу составили 28 условно здоровых лиц в возрасте $(64,0 \pm 9,91)$ лет, мужчин было $12(46,4 \%)$, женщин - $16(53,6 \%)$.

Иммунофенотипирование субпопуляций лимфоцитов периферической крови больных $3 Э О$ кожи век осуществлялось РАР-методом при помощи панели специфических MKAT (CD16, CD25, CD95) в лаборатории иммунологии института.

Статистическая обработка результатов исследования проведена с помощью программы «Statistica 9.0». Для сравнения полученных данных использовался непараметрический метод Манна-Уитни. Различия считались достоверными при уровне значимости р $<0,05$.

РЕЗУЛЬТАТЫ ИССЛЕДОВАНИЯ И ИХ ОБСУЖДЕНИЕ. Средние значения абсолютного и относительного уровня экспрессии антигенов CD16 +, CD25+ и CD95+ лимфоцитами в периферической крови больных $3 Э О$ кожи век до начала лечения и в контрольной группе представлены в таблице 1.
Таблица 1

Уровень экспрессии антигенов CD16 +, CD25+, CD95+ лимфоцитами в периферической крови больных $3 Э О$ кожи век и контрольной группе (M $\pm \mathrm{SD})$

\begin{tabular}{|c|c|c|c|}
\hline Показатели & $\begin{array}{c}\text { 3ЭО век } \\
\text { (n= 165) }\end{array}$ & $\begin{array}{c}\text { Контроль } \\
\text { (n=28) }\end{array}$ & p \\
\hline $\begin{array}{c}\text { Абсолютное кол- } \\
\text { во СD16 (кл./ мкл) }\end{array}$ & $159,3 \pm 87,0 \downarrow$ & $167,3 \pm 81,44$ & 0,653 \\
\hline $\begin{array}{c}\text { Относитительное } \\
\text { кол-во СD16 (\%) }\end{array}$ & $10,8 \pm 4,19 \downarrow$ & $12,7 \pm 11,62$ & 0,389 \\
\hline $\begin{array}{c}\text { Абсолютное кол- } \\
\text { во СD25 (кл./ мкл) }\end{array}$ & $278,7 \pm 160,81 \uparrow$ & $136,9 \pm 56,97$ & 0,000 \\
\hline $\begin{array}{c}\text { Относитительное } \\
\text { кол-во СD25 (\%) }\end{array}$ & $21,8 \pm 18,21 \uparrow$ & $10,7 \pm 2,14$ & 0,001 \\
\hline $\begin{array}{c}\text { Абсолютное кол- } \\
\text { во СD95 (кл./ мкл) }\end{array}$ & $\begin{array}{c}240,9 \pm 136,52 \\
\uparrow\end{array}$ & $118,8 \pm 57,56$ & 0,000 \\
\hline $\begin{array}{c}\text { Относитительное } \\
\text { кол-во СD95 (\%) }\end{array}$ & $17,8 \pm 7,22 \uparrow$ & $9,1 \pm 2,35$ & 0,000 \\
\hline
\end{tabular}

Примечание: $\mathrm{p}-$ уровень значимости различий по критерию Манна-Уитни; $\uparrow-$ значения выше или $\downarrow-$ ниже контрольного.

Как следует из данных таблицы 1, достоверных различий в степени снижения абсолютного и относительного значения уровня экспрессии антигена CD16+ натуральными киллерами (NK-клетки) в

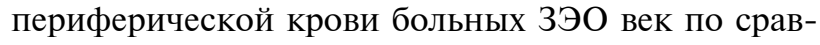
нению с контролем не выявлено. Можно отметить только тенденцию к его снижению.

Абсолютные и относительные показатели содержания антигенов ранней активации лимфоцитов CD25+ (IL-2) и поздней активации лимфоцитов CD95+ (Fas-лиганда) у этих больных значительно выше, чем в контрольной группе и характеризуются высокой статистической значимостью (табл. 1 и рис. 1).

Достоверное увеличение содержания антигенов CD25+ у больных $3 Э 0$ кожи век свидетельствует об активации экспрессии интерлейкина -2 (IL-2), который является фактором аутокринной регуляции роста опухолевых клеток, и его экспрессия сочетается с усилением митоза клеток опухоли. Активируя функционально доминирующий клон клеток, экспрессирующих его рецепторы, IL-2 усиливает апоптоз Т-лимфоцитов и повышает устойчивость к апоптозу онкоцитов [2].

Возрастание проапоптической активности иммуноцитов, опосредуемое через рецептор апоптоза CD95+, приводит к гибели основных субпопуляций лимфоцитов, ответственных за формирование противоопухолевого иммунитета, что сказывается на снижении уровня CD16 (ЕК-клеток).

Повышение содержания в периферической крови больных $3 Э 0$ кожи век CD95+ клеток, экспрессирующих рецептор для FAS-L, свидетельствует об усилении апоптоза Т-лимфоцитов, что оказывает супрессирующее действие на иммунную систему. Поэтому у больных $3 Э О$ кожи век наблюдается сокращение субпопуляций общих Т-лимфоцитов (CD3+), а также Т-хелперов (CD4+) и Т-супрессоров (CD8+) [4]. 

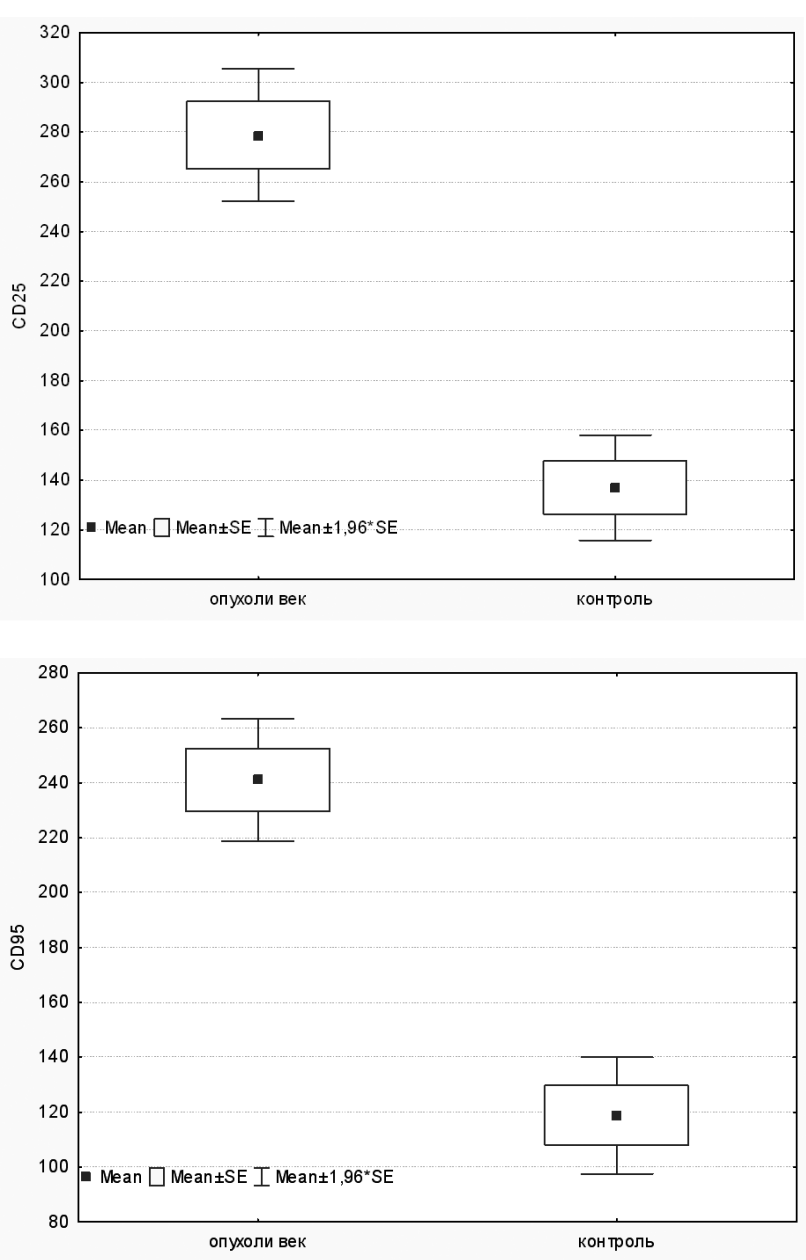

Рис. 1. Средние значения и разброс абсолютных показателей уровня экспрессии антигенов CD25+ и CD95+ (кл/мкл) лимфоцитами периферической крови у больных $3 Э О$ кожи век и в контрольной группе.

Таким образом, сравнительный анализ содержания CD16 +, CD25+ и CD95+ лимфоцитов в периферической крови у пациентов 3ЭО кожи век отличается от таковых у практически здоровых лиц. Снижение клеточного иммунитета сопряжено с повышением уровня клеток с фенотипом CD25 + и CD95+, свидетельствующим об усилении процессов апоптоза Т-лимфоцитов и указывает на снижение ресурсов, необходимых для формирования адаптивных механизмов противоопухолевого иммунитет.

Мониторинговые исследования, проведенные через 6 и 12 месяцев после комбинированного лечения (лучевая терапия + криодеструкция), показали достоверное понижение как абсолютных, так и относительных показателей уровня экспрессии антигенов CD25+ и CD95+ (рис. 2).

Заключение. Таким образом, резорбция опухоли под воздействием физических факторов (лучевая терапия + криодеструкция) с последующей регенерацией поврежденных тканей сопровождается постепенным снижением показателей ранней
(CD25+) и поздней (CD95+) активации лимфоцитов, однако уровня показателей контрольной группы они не достигали, что свидетельствует о недостаточном восстановлении противоопухолевого иммунитета и о необходимости включения в комплекс лечения пациентов злокачественными эпителиальными опухолями кожи век иммунокорригирующих средств.
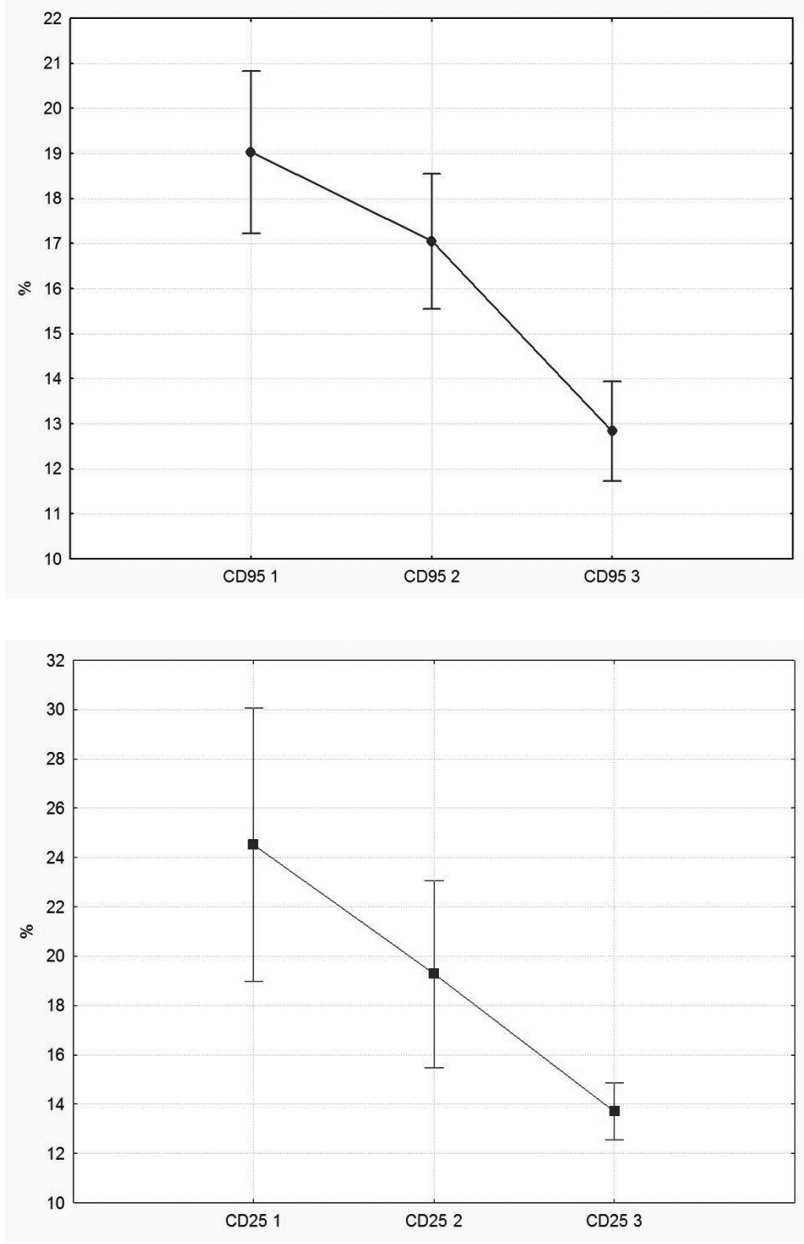

Рис. 2. Динамика средних значений относительных (\%) показателей уровня экспрессии антигенов CD25+ и CD95+ лимфоцитами периферической крови у больных $3 Э О$ кожи век через 6 и 12 месяцев после лечения $\left(\mathrm{CD}^{2} \mathrm{p}_{1-2}=0,04\right.$, $\left.\operatorname{CD} 9 p_{2-3}=0,000 ; C_{1-2} 25 p_{1-2}=0,02, C D 25 p_{2-3}=0,001\right)$.

\section{ЛИТЕРАТУРА}

1. Анищенко И. С. Плоскоклеточный рак кожи: клиника, диагностика, лечение / Анищенко И. С., Важенин А. В. - Челябинск, 2000. - 210 с.

2. Молекулярные механизмы взаимодействия опухоли и иммунной системы / Бережной Е. Е., Гнучев Н. В., Георгиев Г. П. [и др.] // Вопросы онкологии. - 2008. T.54. - № 6. - С. 669-683.

3. Растворимые антигены CD38 и CD95 при раке молочной железы / Новиков В. В., Алясова А. В., Уткин О. В. [и др.] // Российский биотерапевтический журнал. 2005. - T.4 - № 3. - С.48-53. 
4. Сафроненкова И. А. Состояние иммунной системы больных злокачественными эпителиальными опухолями век / И. А. Сафроненкова // Офтальмол. журн. - 2012. - № 1. - С.39-41.

5. Хлебникова А. Н. Гистологические варианты базальноклеточного рака кожи / Хлебникова А. Н., Казанцева И. А. // Рос. журн. кожн. и венерич. бол. 2000. - № 2. - С. 4-6.

6. Шенталь В. В. Рак кожи / Шенталь В. В., Пустынский И. Н., Малаев С. Г. // Мед помощь. - 2000. № 4. - C.6-10.

7. Devis D. Phototoxicity: environmental hazard and therapeutic tool / Devis D., Marvin W. // Drug Topics. 2001. - V.145. - № 14. - P. 41-51.
8. Incidence Estimate of Nonmelanoma Skin Cancer in the United States, 2006 / Rogers H. W., Weinstock M. A., Harris A. R. [et al] // Arch. Dermatol. - 2010. - V.146. № 3. - P. 283-287.

9. Need for a New Skin Cancer Management Strategy / van der Geer S., Reijers H. A., van Tuijl H. F. J. M, [et al.] // Arch. Dermatol. - 2010. - V.146. - № 3. P.332-336.

10. Stern R. S. Prevalence of a History of Skin Cancer in 2007 / Stern R. S. // Arch. Dermatol. - 2010. - V.146. № 3. - P.279-282.

Поступила 20.06.2012 Рецензент д. М. н. С. И. Полякова

\title{
THE EXPRESSION LEVEL OF ANTIGENS CD16+, CS25+ AND CD95+ BY LYMPHOCYTES OF THE PERIPHERAL BLOOD IN PATIENTS WITH MALIGNANT EPITHELIAL TUMOURS OF THE EYELIDS DURING COMBINED TREATMENT \\ Safronenkova I. A. \\ Odessa, Ukraine
}

There was studied the expressional level of subpopulation of CD16+, CD25+, CD95+ lymphocytes in 165 patients with malignant epithelial tumors (MET) of the skin of the eyelids and in 28 conditionally healthy persons using the same monoclonal antibodies. It has been established the significant increasing of antigens CD25+ and CD95+ expression and decreasing of CD16+ expression of MET of skin of eyelid in comparison with normal. It testifies to the decreasing of antitumor immunity in patients with MET of the skin of the eyelids and to acquisition of ability of immune system to stimulation of growth of tumoral cells. Significantly The significant decreasing of CD25+ and CD95+ expression in 6 and 12 months after combined treatment (radiotherapy + cryodestruction) testifies to the beginning of restoration of immunity in patients with MET of the eyelids scin.

УДК 617.723-006.81.04-097-092.8-085.849.19

\section{ОСОБЕННОСТИ ВЗАИМОДЕЙСТВИЯ КЛЕТОК МЕЛАНОМЫ С МАКРОФАГАМИ ПЕРИФЕРИЧЕСКОЙ КРОВИ У БОЛЬНЫХ МЕЛАНОМОЙ ГЛАЗА ПРИ РАЗЛИЧНОМ КЛИНИЧЕСКОМ ТЕЧЕНИИ ОПУХОЛЕВОГО ПРОЦЕССА}

\author{
Л. Н. Величко, к. М. Н., В. В. Вит, д. м. Н., проф.
}

ГУ «Институт глазных болезней и тканевой терапии им. В. П. Филатова НАМН Украины»

\begin{abstract}
Вивчено особливості взаємодії меланомних клітин з макрофагами периферичної крові у 22 хворих на увеальну меланому. Проводилось вивчення макрофаг-пухлинного розеткоутворення та ступеня цитотоксичного пошкодження пухлинних клітин макрофагами у хворих з різною ефективністю лікування. У хворих на увеальну меланому з метастазами встановлено достовірне підвищення рівня макрофаг-пухлинного розеткоутворення, а також відсутність цитотоксичного пошкодження пухлинних клітин макрофагами, порівняно з групою хворих з прогресивним зменшенням пухлини. Регресія меланоми супроводжується цитотоксичним ушкодженням пухлинних клітин.
\end{abstract}

Ключевые слова: увеальная меланома, опухолевые клетки, макрофаги, метастазирование

Ключові слова: увеальна меланома, пухлинні клітини, макрофаги, метастазування

Введение. Изучение значения микрометастазов является одной из важных проблем онкологии. Но уже сегодня можно говорить о том, что наличие опухолевых клеток в крови в большинстве случаев определяет неблагоприятный прогноз [5].
Однако подобное мнение не является окончательным, так как большинство одиночных метастатических клеток-эмболов не дают начало развитию истинных метастазов. Остается неясной природа

(с) Л. Н. Величко, В. В. Вит, 2012 